\title{
Dialogic Learning in the Training of Nurses
}

\author{
Maria Dolores Bardallo ${ }^{1}$, José Luis Medina ${ }^{2}$, Adelaida Zabalegui ${ }^{3}$ \\ ${ }^{1}$ Department of Nursing, International University of Catalunya, Barcelona, Spain \\ ${ }^{2}$ Department of Education, Barcelona University, Barcelona, Spain \\ ${ }^{3}$ Hospital Clinic of Barcelona, Barcelona, Spain \\ Email: azabaleg@clinic.ub.es
}

Received May 24 $4^{\text {th }}$, 2012; revised June $26^{\text {th }}$, 2012; accepted July $12^{\text {th }}, 2012$

\begin{abstract}
Copyright (C) 2013 Maria Dolores Bardallo et al. This is an open access article distributed under the Creative Commons Attribution License, which permits unrestricted use, distribution, and reproduction in any medium, provided the original work is properly cited.
\end{abstract}

\begin{abstract}
This document, of a theoretical nature, presents a reflection on dialogic rationality in nursing instruction, based on the principles that define this postmodern approach to education. The principles governing the development of dialogic pedagogy fall within the very epistemology of care, defining the explicit and implicit relationships that exist between knowledge and the practice of care. The objective of the document is: To share a reflection on the rationality that permeates education in nursing and to present a theoretical framework for transforming and emancipating teaching practice in nursing. The conclusions of the document are: 1) The dialogic orientation of nursing instruction provides a view of the reality of care that is consistent with the meaning of nursing practice; 2) It favors the creation of intersubjectivities between teacher and student that generate development and personal and professional growth that transcend the educational act to embed themselves in care practice itself and the relationship with the person being cared for; and 3) It represents a framework for transforming care practice and the power relationships established through the legitimized discourses.
\end{abstract}

Keywords: Dialogic Learning; Nursing

\section{About Dialogic Learning}

Based on the constructivist approach of Vygotsky (1979), on social (Beck, 1998; Giddens, 1994; Habermas, 2003) and educational (Freire, 1997) theories, the concept of dialogic learning in Spain was formulated by Flecha (2003) after several years of research in the field of adult learning. Along the same transformative lines, authors such as Scribner (1988) and Brunner (1988) have demonstrated how people resolve conflict situations or confront new learning through dialogue. People interact and help each other by sharing their knowledge or by confronting new challenges.

Societies are becoming increasingly dialogic (Flecha, Gómez, Puigvert, and Beck, 2001) due to the fact that dialogue is increasingly present as a form of relationship and exchange in all environments, both public and private, at a political and social level. Sociological analyses show the increased prominence of dialogue in relation to industrial society.

Under the new social model, the principles of traditional modernity are being radicalized to open up new forms of coexistence that are more egalitarian and inclusive; these new forms permit dialogue and joint reflection with other cultures, with people who have different life options, where gender and age cease to be perceived as a burden to become attributes of diversity and socio-cultural richness.

Not only are dialogic realities expanding, but also dialogic purposes. In the field of health, as in education, the increased participation of the main actors is a fact, as is the resolution of conflicts through dialogue and mediation, demonstrating that it is possible to attain equality in difference, an equality of rights that includes respect for diversity (Aubert, Duque, Fisas, and Valls, 2004).

The transition from the industrial society to the knowledge society has been accompanied by a radical crisis in the subject-object division of traditional modernity. Modernity is a philosophical and sociological concept, which can be defined as the proposal of imposing the reason as transcendental rule to the society. In this way, ideal of progress and critical thinking are constructed in the light of reason that provides absolute truths. The breakdown of this division has given rise to opposing paths: one, the dissolution of the subject and, therefore, the renunciation of any transformative orientation; the other, intersubjectivity (defined as the creation of shared spaces for learning and social interaction in which meanings are created and agreed by a human group) through which transformation is undertaken jointly with the persons involved, through dialogue and discussion.

Throughout history, authors have offered numerous proposals on the subject of social change based on education. Among others, there are Rousseau, who placed the pupil at the center of the process, or Dewey, with his democratic pedagogy, Freire and liberation pedagogy, etc. All of these take on increasing importance in the dialogic area, in which a change in the teacher-student relationship is emphasized. Freire expanded this dialogue to the entire educational community by considering that learning is influenced by the environment in which the student lives and not only by the teacher-student relationship.

The development of the social sciences has proved Freire right. Habermas places dialogue at the center of his sociological thesis. Giddens clarifies transformations driven by social 
movements. Beck talks about reflexive modernization. Dialogue, reflexivity and transformation, the three pillars that support dialogic learning. In the field of nursing, dialogue with other disciplines and with persons receiving nursing care is a challenge and a growing necessity for democratizing care and incorporating its protagonists' presence and voices. Care, from the standpoint of the inclusion of culturally created health practices, implies recognizing the knowledge and the meanings that people construct intersubjectively to make sense of their health and disease experiences. Care, understood from this dialogic perspective, opens the door to the transformation of professional practice and disciplinary development under conditions of equality with disciplines that even today situate their discourse in spaces of power legitimized by control and exclusion by virtue of the knowledge deposited in them.

From the perspective of dialogic action, protagonism in care or in education is not exercised by the dominant elites, or by doctors, nurses, or teachers, or even by the proclaimed majority. It is found in intersubjectivity. Emphasizing intersubjectivity as the center of creation and decision-making means overcoming objectivist ideas.

The approach to the reality of care or to the educational reality must be done critically in order to transform it and transform ourselves. To do this, cooperation is achieved through dialogue and communication, thus avoiding falling into power relationships and the conquest of spaces that do not correspond to one, relationships that are always associated with some form of violence (Aubert et al., 2004). This involves the horizontalization, making egalitarian, of the acts of caring/being cared for and teaching/learning, preventing the hierarchical distribution of roles among those who provide care or teach (superiors), and those who are cared for or taught (inferiors).

This characteristic is fundamental if we want a society with critical-thinking persons who are responsible for their own health and committed to the health of the community, who are capable of assuming empowerment. Autonomous individuals, people who are collaborative, responsible and committed to their own development and lifelong learning, have all skills that are central to the construction of a knowledge society.

\section{Five Principles for Transforming Care Practice and Nursing Education}

\section{Egalitarian Dialogue}

A dialogue is egalitarian when the value of the different contributions is attributed to the arguments that sustain them, without being measured by the positions of power held by those who submit them (Flecha, 2003: p. 14).

The supposition that knowledge is mediated by power relationships is particularly significant in the field of nursing. Perhaps the most significant contribution of this socio-critical theory has been the recognition of the influence that social institutions and the socio-cultural context exerts on how healthcare practice and the teaching of nursing professionals is understood, from which the manner of taking decisions about transmitting knowledge and relating to students is derived.

When a nursing instructor imposes his or her truth on a student under the coercion, explicit or implicit, of the power to give the student a failing grade, does not give any alternative to the student abusing of the established wisdom of authority. This reveals knowledge to be an instrument of power rather than a potential of service enabled by the possession of knowledge.
The instructor is not only teaching a nursing procedure, he or she is also modeling the use of knowledge. The instructor is revealing a model of a relationship with the "Other", whether this is the student or a person being cared for, based on what the "Other" possesses instead of what the "Other" is. In most cases this is unconscious.

Egalitarian dialogue also has a mutual advantage: the teacher and student learn and grow together because both reconstruct their interpretations of reality based on the arguments presented (Adorno \& Popper, 1973).

In the theory of Habermas (2003) on Communication Action, he has pointed out the need of dialog and consensus in order to promote human relations. Besides, Beck and Giddens (1994) had identified transformational perspective that includes the reflexive process in human relations. Moreover, Freire (1997) had included the egalitarian dialogue in cases of extreme inequality.

Through education based on egalitarian dialogue, acquiring the skills required to survive in the knowledge society is easier and more profound than with traditional teaching methods. The culture of egalitarian dialogue brings us closer to responsible social participation, to active citizenship. It is a commitment to sustained transformation and the search for new ways to a more participatory democracy.

In the field of nursing, the culture of dialogue is represented by the humanist theory of Paterson and Zderad (2007), who, influenced by the thinking of Hüsserl, Dewey, Buber and Marcel, conceptualize care as an experience of encounter between the nurse and the patient. In this encounter the participants construct their own meaning of being and becoming through intersubjective dialogue. In this intersubjectivity, the nurse and the patient share their knowledge, their experiences and their way of being and existing in the world. Each of them contributes an experience that will facilitate a dialogue through which both will learn and initiate a process of personal growth. Therefore, the nurse-patient relationship is an integral part of care and plays a role in it through an intersubjective transaction, one of human dialogue about a shared situation in which both are present (Meleis, 1997).

In our opinion, education as a form of care participates in the philosophy expressed by Paterson and Zderad for the purely healthcare environment. As a result, we considered it appropriate to assimilate the nurse-patient relationship into that posed in a teacher-student relationship. Both situations pursue the objective, at the very least, of the development and growth of the person being cared for/educated. Both are human actions of a moral nature in which an intersubjectivity is created that gives meaning to the encounter.

The dialogue between teacher and student is built on everyday experiences in the practice of care, progressively incorporating (although not in all cases) elements of their own experiences that connect with the teaching-learning experience in which both are immersed. Educational interaction based on communicative action promotes self-esteem in the participants and generates knowledge through dialogue-based discussion in which the incursions of one or the other are not categorized as better or worse, but are appreciated as different on the horizontal plane of the relationship.

\section{Cultural Intelligence}

With their interpretive categories, privileged groups determine the social valuation of their forms of communication as 
intelligent and those of less privileged sectors as deficient (Flecha, 2003: p. 20).

The most notable contributions to overcome this approach come from research that initially differentiates between fluid intelligence and crystallized intelligence and, later, between academic intelligence and practical intelligence, with the latter emphasizing the tacit knowledge that we acquire through action and daily experience (Stenberg \& Wagner, 1986; Scribner, 1988). Thus, it can be demonstrated that persons categorized as slow in academic environments maybe very effective in work environments or daily life.

Cultural intelligence incorporates academic and practical intelligence and the other human abilities of language and action that make it possible to reach agreement in different social environments. However, in contrast to each of these, cultural intelligence presupposes interaction, interaction based on community action, using verbal and non-verbal means, through which agreements are reached in cognitive, ethical, aesthetic, and affective environments (Flecha, 2003).

Cultural intelligence exists in all persons. It is a universal capacity because all persons have the innate ability to communicate through language. Some develop it through academic and theoretical training, others through more practice-based training and still others through the school of life. But all of them can transfer these skills from one environment to another if the conditions are right.

The hierarchical division of knowledge into theoretical knowledge and practical knowledge, and the greater value of truth placed on the former, produces a negative effect of distrust in the abilities of people who possess practical knowledge obtained in social and work environments, far removed from academia. Historically, consideration of nursing as an applied science has made it dependent on more academically qualified types of learning which have hindered its insertion in the current of legitimized knowledge of the scientific community. However, the inclusionary category of cultural intelligence proposed by the dialogic approach is closer to the epistemology of care and to educational practice, a category from which analysis and comprehension can be oriented towards active participation of people in their health or teaching-learning processes. It allows for a commitment to horizontal relationships based on the abilities of the main actors, as opposed to their deficits. It advocates recognition of the cultural practices of people and the complementarity contributed by experts.

Educational interaction based on dialogue makes mutual recognition and interactive self-confidence one of its fundamental pillars. This environment of trust-based encounters favors cultural transference by placing value on the contribution of each protagonist in the relationship. It is a tool for dialogic creativity or knowledge generation based on active listening and participation. It is an opportunity that should be taken into account in teacher-student interaction and fostered by health and education organizations.

\section{Transformation}

The idea of transformation is at the heart of any educational process. On this subject, Paulo Freire (1997) stated that we are not beings of adaptation but rather of transformation. This fact, so evident in education, can be analyzed from very different perspectives. From that of traditional modernity, transformation occurs because someone is considered a subject and the trans- formative role is attributed to other people, based on instrumental rationality in which a subject acts upon an object to transform it. This is the rationality currently operating in the practice of care and education, in spite of the fact that transforming initiatives are taking place in both environments. The postmodern perspective denies the possibility and benefit of transformation (Giroux \& Flecha, 1992). The reproduction model (Althusser, 1992), which maintained that education reproduced social inequalities and denied the possibility of overcoming these, has been widely superseded by the transformative theses of Habermas (2003) or Giddens (1994). If society and education are merely a consequence of structures, the question we could ask ourselves is where do people fit in, what role does the movement of social groups play or how is new knowledge created. The dual character of action has been demonstrated with theories such as those of Habermas (system and lifeworld) and Giddens with his structure and human agency. Therefore if, in addition to structures, the intersubjective relationship of people (lifeworld-human agency) creates society and education, political and pedagogic actions must consider what orientation they want to give to the transformations they inevitably produce (Flecha, 2003).

The dialogic perspective supports the possibility and the advantage of transformations, provided they are produced within a framework of equality and participation, dialogue and inclusive consensus. The product of intersubjectivity represents the differences, recognized and unified through the consensus of the people who participate. Moving from positions of invisibility to positions of shared knowledge creation substantially changes the situation of the people involved in an educational interaction. It is this dialogic, communicative, creation that transforms structures and people that makes social, occupational and intellectual emancipation possible. Thanks to the transformation processes occurring in health and educational institutions based on dialogic action, a centrifugal dynamic is being produced that extends, more or less explicitly, to the entire community. Research-action groups, both in health and in education, are an example of this.

\section{Instrumental Dimension}

From the most traditional analytical perspectives on educational analysis, there is a tendency to juxtapose, to enforce a dichotomy between, the alternatives of instrumental learning versus dialogic learning. The most conservative positions tend to condemn the dialogic alternative, as they consider that democratizing teaching is synonymous with a loss of quality of technical and scientific learning. On the other hand, other innovative alternatives in pedagogic renewal propose training that is more humanistic than technical. Other positions, in a reductionist interpretation of Habermas's theory, contrast the ideas of communicative learning and instrumental learning (Flecha, 2003).

The traditional nursing curriculum is based, mainly and as corresponds to rationality, on instrumental learning, despite the vehement incorporation of the holistic vision of the person into nursing language. This could give the impression that professional competence would be unattainable if not for the instrumental orientation of learning. However, the very epistemology of care practice clashes with this initial impression.

From its holistic and inclusive vision, dialogic learning promotes the acquisition of instrumental abilities in those areas 
where this type of knowledge is pertinent, without abandoning its practical-dialogic rationality. It does not try to avoid instrumental learning. It rejects the instrumentalization of the learning process, through which objectives and procedures are constructed outside of people, alienating them by putting forth arguments of a technical nature that serve minority and exclusionary interests. To build care or educational interaction from dialogic rationality means a commitment to doing this with people and for people, around whom the professional practices revolve. Dialogic interaction places us in the position of thinking about what other people say, about what we say and how we argue this. When dialogue is truly equal, it promotes intense reflection because there is a need to understand the arguments of others and to create arguments of one's own (Giddens, 1994).

\section{Creation of Meaning}

Humanity is heading for the challenge of recreating the meaning of its existence, lost in the tangled web of the industrial and technological revolution. The principal point of reference lies within the each person. Human being has to recreate the meaning of his existence that has been lost with the industrial revolution and technology. It is common to hear people talk about the loss of values. We could instead assert that values are changing, that they are being recreated in a society that is open to many possibilities thanks to education and access to information sources. It is true that we cannot resort to tradition to find meaning in our lives, but this doesn't mean that there are no values; there are other values that arise from the uncertainty generated by a society in which options are ever broader and more diverse. This means that the person has increasing control over his or her own life and must define a life project. Through dialogue and shared reflection, people find the support necessary to define their life project in a much more informed way.

Dialogic learning breaks with social determinism; it equips the mind appropriately so that people can take informed decisions from the multiple options offered to them (Aubert et al., 2004). Nursing practice today is directed at persons with a greater knowledge of their environment, with greater possibilities of accessing knowledge and with diverse positions with regard to their health and quality of life. Intercultural coexistence is generating new values and diverse practices in individual and collective healthcare. In this multicultural context, nursing practice finds its meaning in the empowerment of the persons being cared for, in participation to transform health services and in the transmission of these values to future professionals. Education understood from the dialogic perspective fosters the empowerment of students by considering them as capable subjects within the learning process, at the same time as it favors the teacher's dialogic practice, both in the educational environment and in the care environment.

\section{Conclusion}

The social changes we are witnessing favor dialogue and consensus to break down previously insurmountable barriers.
Symmetric dialogue facilitates the acquisition and development of skills that companies today consider necessary for obtaining a job. In this dialogue, people are learning to communicate, to find ways of understanding and to overcome difficulties.

The dialogic orientation of nursing instruction provides a view of the reality of care that is consistent with the meaning of nursing practice and favors the creation of intersubjectivities between the teacher and student, generating development and personal and professional growth; these are intersubjectivities that transcend the educational act to become embedded in the practice of care itself and in the relationship with the person being cared for.

It represents a framework for transforming care practice and the power relationships established through the legitimized discourses.

\section{REFERENCES}

Adorno, T., \& Popper, K. (1973). The discussion of positivism at the german sociology. Barcelona: Grijalbo.

Althusser, L. (1992). The future in long. Barcelona: Destino.

Aubert, A., Duque, E., Fisas, M., \& Valls, R. (2004). Dialoging and transforming: A critical pedagogy for the XXI century. Barcelona: Graó.

Beck, U. (1998). A society of risck: Towards a new modernity. Barcelona: Paidós.

Beck, U., \& Giddens, A. (1994). Reflexive modernization. Politics, tradition and aesthetics in the modern social order. Cambridge: Polity Press.

Brunner, J. (1988). Cognitive development and education. Madrid: Morata.

Flecha, R. (2003). Sharing words. Learning of older people through dialog. Barcelona: Paidós.

Flecha, R., Gómez, J., Puigvert, L., \& Beck, U. (2001). Contemporary sociological theory. Barcelona: Paidós.

Freire, P. (1997). The shadow of this tree. Barcelona: Roure.

Giddens, A. (1994). Modernity and identity of the ego. Barcelona: Península.

Giroux, H., \& Flecha, R. (1992). Educative equality and cultural differences. Barcelona: Roure.

Habermas, J. (2003). Theory of comunication acction. Madrid: Taurus.

Meleis, A. I. (1997). On transitions and knowledge development. Nursing beyond art and science: Annnotate edition. Tokyo: Japan Academy of Nursing Science.

Paterson, J., \& Zderad, L. (2007). Humanistic nursing. Gutenberg eBook.

Scribner, S. (1988). Head and hand: An action approach to thinking. New York: Teachers College of Columbia University.

Stenberg, R. J., \& Wagner, R. K. (1986). Practical intelligence. Cambridge: Cambridge University Press.

Vygotsky, L. S. (1979). The development of psychological higher processes. Barcelona: Crítica. 